\author{
Jurnal \\ Kardiologi Indonesia \\ J Kardiol Indones. 2014;35:296-302 \\ ISSN $0126 / 3773$
}

\section{Review Article}

\title{
Varicose Vein
}

\author{
Putri Septiani*, Heru Sulastomo**
}

* PPDS-I Kardiologi dan Kedokteran Vaskuler Fakultas Kedokteran Universitas Sebelas Maret, RSUD dr.Moewardi Surakarta

** SMF Kardiologi dan Kedokteran Vaskuler Fakultas Kedokteran Universitas Sebelas Maret, RSUD dr.Moewardi Surakarta
Varicose vein is a common problem in vein. It is a dilated, elongated, and tortuous vein. It used to be a cosmetic problem, but nowadays it has become a more serious problem, since it can affect quality of life. It usually occurs in the inferior extremities. The venous system is divided into superficial vein, deep vein, perforator vein, and intramuscular sinus venosus. Pathological conditions that usually occur in the vein system are obstruction and valve incompetence. The risk factors of varicose vein are: elderly, history of family with varicose vein, pregnancy, occupation that requires long standing, sedentary life style, and obesity. Ultrasonography (USG) duplex is the most recommended modality to diagnose varicose vein. The classification of this disease is based on chronic venous disease classification, the CEAP (Clinical, Etiology, Anatomy, Pathophysiology) classification. The management for varicose vein includes intervention (sclerotherapy, endovenous ablation, and surgery) and non-intervention (education, compression stocking, and pharmacology) therapy.

(J Kardiol Indones. 2014;35:296-302)

Keywords: varicose vein, CEAP classification, diagnosis, management 
Jurnal

\title{
Tinjauan Pustaka
}

Kardiologi Indonesia

J Kardiol Indones. 2014;35:296-302

ISSN 0I 26/3773

\section{Vena varikosa}

\author{
Putri Septiani*, Heru Sulastomo**
}

\begin{abstract}
Vena varikosa merupakan masalah yang umum terjadi pada pembuluh darah vena. Vena varikosa adalah vena yang terdilatasi, memanjang, dan berliku-liku. Dahulu, vena varikosa menjadi masalah kosmetik, namun sekarang ini telah menjadi masalah yang lebih serius, karena penyakit ini dapat mempengaruhi kualitas hidup. Penyakit ini biasa terjadi di ekstremitas bawah. Sistem vena di ekstremitas inferior terbagi menjadi vena superfisial, vena dalam, vena perforator, dan sinus venosus intramuskular. Kondisi patologis yang umum terjadi pada sistem vena adalah obstruksi dan inkompetensi katup. Faktor risiko terjadinya vena varikosa antara lain: usia tua, riwayat keluarga dengan vena varikosa, kehamilan, pekerjaan yang membutuhkan berdiri lama, gaya hidup sedenter, dan obesitas. Ultrasonografi (USG) duplex merupakan modalitas yang paling direkomendasikan untuk mendiagnosis vena varikosa. Klasifikasi dari penyakit ini adalah berdasarkan klasifikasi penyakit vena kronis, yaitu klasifikasi CEAP (Clinical, Etiology, Anatomy, Pathophysiology). Penanganan vena varikosa meliputi terapi intervensi (skleroterapi, endovenous ablation, dan pembedahan) serta non-intervensi (edukasi, stoking kompresi, dan farmakologi).
\end{abstract}

(J Kardiol Indones. 2014;35:296-302)

Kata kunci: vena varikosa, klasifikasi CEAP, diagnosis, penanganan

$\mathrm{V}$ ena varikosa merupakan masalah yang umum terjadi pada pembuluh darah vena. Beberapa orang menganggap hal tersebut merupakan hal yang normal. Semakin tua usia seseorang, semakin besar kemungkinan vena varikosa akan terlihat. Kebanyakan orang dengan usia lebih dari 60 tahun memiliki vena varikosa. ${ }^{(1)}$

Vena varikosa dapat terjadi di ekstremitas atas

\footnotetext{
Alamat Korespondensi

* dr.Putri Septiani, PPDS-I Kardiologi dan Kedokteran Vaskuler Fakultas Kedokteran Universitas Sebelas Maret, RSUD dr.Moewardi Surakarta, E-mail: putrisepti87@gmail.com

** dr.Heru Sulastomo, Sp.JP, FIHA, SMF Kardiologi dan Kedokteran Vaskuler Fakultas Kedokteran Universitas Sebelas Maret, RSUD dr.Moewardi Surakarta, E-mail: herusulastomo@gmail.com
}

maupun ekstremitas bawah. Namun vena varikosa di ekstremitas atas sangat jarang terjadi. Berdasarkan beberapa sumber, hingga saat ini hanya ditemukan sedikit kasus vena varikosa yang melibatkan ekstremitas atas. $^{(2-4)}$

Pengetahuan mengenai vena varikosa diharapkan dapat meningkatkan pemahaman bagi klinisi dalam menegakan diagnosa dan menentukan terapi pada pasien vena varikosa. Tujuan dari tulisan ini adalah untuk membahas faktor risiko, diagnosis, dan penanganan vena varikosa berdasarkan tinjauan literatur terbaru sehingga dapat bermanfaat untuk menambah pemahaman mengenai vena varikosa dan membantu dalam meningkatkan ketepatan diagnosa dan terapi vena varikosa. 
Jurnal Kardiologi Indonesia

\section{Anatomi Sistem Vena Ekstremitas Inferior}

Untuk lebih memahami mengenai area yang terkena vena varikosa, berikut ini adalah skema anatomi dari sistem vena ekstremitas inferior.

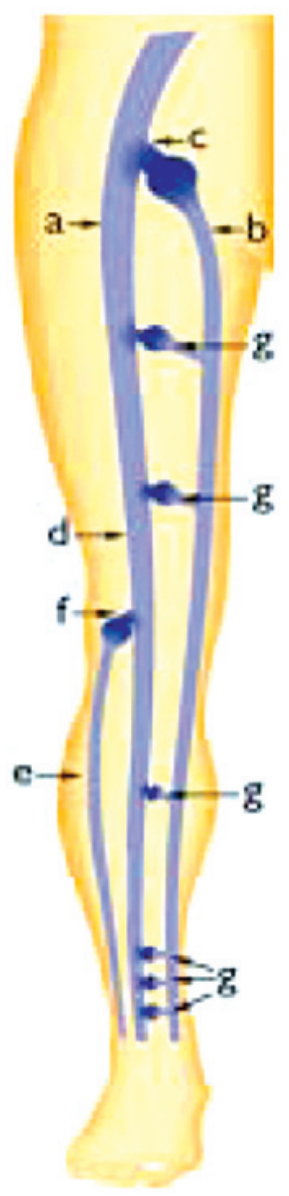

Gambar 1. Anatomi sistem vena ekstremitas inferior ${ }^{5}$ a) v. femoralis, b) v. saphena magna, c) saphenofemoral junction, d) v. poplitea, e) v. saphena parva, f) saphenopopliteal junction, g) vena perforator

\section{Kondisi Patologis Pada Sistem Vena}

Obstruksi vena paling sering terjadi karena trombosis vena, namun dapat juga terjadi dari kompresi vena (tumor, fraktur, hematom, aneurisma arteri, dsb). Faktor yang dapat merangsang trombosis vena antara lain vein injury, flow stasis (inactive muscle pump karena kurang-gerak, imobilisasi karena bedrest atau paralisis), hiperkoagulabilitas darah (pada pasien post-operative atau gangguan koagulasi intrinsik) dan kombinasi dari hal-hal di atas dapat terjadi pada pasien dengan multipel trauma.

Inkompetensi katup dapat disebabkan defek katup kongenital atau terjadi karena komplikasi dari trombosis vena dan hipertensi vena. Inkompetensi katup kongenital terjadi di vena superfisial dan vena perforator. Inkompetensi vena dalam dapat menjadi komplikasi dari trombosis vena dalam sebelumnya meskipun riwayat trombosis vena dalam terdapat pada $<50 \%$ pasien. ${ }^{6}$

\section{Faktor Risiko Vena Varikosa}

Hal-hal di bawah ini dapat menjadi faktor risiko terjadinya vena varikosa: ${ }^{7,8}$

1. Herediter

Faktor keturunan seperti kelemahan dinding vena, peningkatan disfungsi valvular primer atau agenesis, dan faktor genetik lain dapat meningkatkan kemungkinan terjadinya vena varikosa.

2. Kehamilan

Sekitar $70-80 \%$ pasien mengalami vena varikosa selama trimester pertama, ketika uterus mulai sedikit membesar. Pada trimester kedua, 20-25\% pasien masien mengalami vena varikosa, dan $1-5 \%$ mengalaminya pada trimester ketiga.

3. Penuaan

Insidensi vena varikosa meningkat seiring bertambahnya umur, oleh karena itu kerusakan pada dinding vena kemungkinan lebih menonjol pada vena pasien yang lanjut usia.

4. Gaya Hidup

Insidensi vena varikosa dapat meningkat pada penggunaan korset atau baju yang ketat, pada orang dengan obesitas, pada penggunaan toilet duduk, serta pada orang dengan pekerjaan yang membutuhkan waktu berdiri lama.

\section{Gejala dan Tanda Vena Varikosa}

Gejala yang dapat timbul pada vena varikosa antara lain ${ }^{(8)}$ :

- Rasa berat di ekstremitas bawah (saat berdiri atau duduk lama) 
- Rasa nyeri di ekstremitas bawah (saat berdiri atau duduk lama)

- Sensasi terbakar (neuropati vena)

- Rasa gatal (inflamasi kutaneus)

- Rasa kram di malam hari (pengurangan edema pada posisi berbaring)

\section{Pemeriksaan Vena Varikosa}

Beberapa pemeriksaan berikut dapat dilakukan untuk menegakkan diagnosis vena varikosa:

1. Venografi

Venografi terdiri dari 2 macam, yaitu ascending venography dan descending venography. Ascending venography dilakukan dengan injeksi zat kontras di dorsum pedis dengan visualisasi kontras yang naik sepanjang sistem vena dalam di ekstremitas inferior. Descending venography dilakukan dengan injeksi zat kontras di vena femoralis komunis pada posisi tubuh semivertikal dan pasien diminta melakukan manuver Valsava. ${ }^{9,10}$

2. Ambulatory Venous Pressure (AVP)

Pengukuran AVP dilakukan dengan menusukkan jarum di v.dorsalis pedis yang kemudian disambungkan pressure transducer. Tekanan diukur saat istirahat dan setelah dilakukan latihan. Selama pengukuran AVP pada ekstremitas normal pada saat latihan, tekanan darah vena turun dengan cepat (hingga $\leq 30$ detik) dan kembali melalui kapiler dengan lambat ( $\geq 20$ detik). Pada inkompetensi katup, refluks terjadi saat latihan, sehingga tekanan darah vena tetap tinggi karena kembalinya darah melalui katup yang inkompeten terjadi dengan cepat. ${ }^{9,10}$

3. Pletysmography

Ini merupakan pemeriksaan noninvasif yang dilakukan dengan melingkarkan air chamber di sekeliling betis dan dihubungkan dengan pressure transducer dan chart recorder. Pengukuran dilakukan pada posisi istirahat dan posisi berdiri. Parameter pengukurannya adalah venous filling index (VFI), di mana nilai normalnya adalah $<2$ $\mathrm{mL} / \mathrm{s} .{ }^{9,10}$

4. Venous Duplex Imaging

Imaging pada vena varikosa hendaknya meliputi hal-hal berikut:

- Adanya obstruksi atau refluks pada vena dalam di ekstremitas bawah

- Obstruksi pada v.saphena magna
- Obstruksi pada v.saphena parva

- Lokasi dan perluasan cabang vena varikosa

- Lokasi vena perforator yang inkompeten

Sistem ultrasonografi (USG) duplex standar dengan $B$-mode imaging resolusi tinggi, analisis pulsed Doppler spectral waveform, dan color-flow imaging dapat digunakan untuk scanning vena extremitas bawah. Color-flow imaging bermanfaat dalam pemeriksaan duplex dengan membantu dalam identifikasi arteri dan vena secara cepat, sehingga mengurangi waktu pemeriksaan, terutama untuk pemeriksaan pembuluh darah tibia.

Transducer bervariasi dibutuhkan dalam pemeriksaan duplex vena ekstremitas bawah secara lengkap. Transducer frekuensi-rendah (2-3 MHz) merupakan yang paling baik untuk pemeriksaan v.cava inferior dan v.iliaca, sedangkan transducer dengan frekuensi lebih tinggi $(5-10 \mathrm{MHz})$ secara umum digunakan untuk memeriksa vena ekstremitas bawah. Vena superfisial biasanya dapat tampak dengan transducer frekuensi tinggi. Secara umum, transducer dengan frekuensi tertinggi yang dapat memberikan kedalaman penetrasi yang adekuat hendaknya digunakan untuk memperoleh kualitas gambar yang paling baik. ${ }^{9,11}$

Dari berbagai pemeriksaan di atas, 3 di antaranya sudah jarang dilakukan. Saat ini, berdasarkan The National Institute for Health and Care Excellence (NICE) Guideline untuk vena varikosa, pemeriksaan duplex ultrasound merupakan yang direkomendasikan untuk menegakkan diagnosis. ${ }^{12}$

\section{Klasifikasi Vena Varikosa}

Klasifikasi vena varikosa berdasarkan kriteria klasifikasi untuk penyakit vena kronis, yaitu klasifikasi CEAP. ${ }^{13}$

\section{Manajemen Vena Varikosa}

Edukasi mengenai hal-hal berikut pada pasien perlu diberikan dalam penanganan vena varikosa: ${ }^{12}$

1. Penurunan berat badan (bagi penderita dengan obesitas)

2. Aktivitas ringan-sedang

3. Menghindari faktor-faktor yang dapat memperburuk gejala 
Tabel 1. CEAP Classification

\begin{tabular}{|c|c|c|c|}
\hline Clinical Classification & Etiologic Classification & Anatomic Classification & Pathophysiologic Classification \\
\hline $\begin{array}{l}\text { C0: no visible or palpable signs of venous } \\
\text { disease }\end{array}$ & Ec: congenital & As: superficial veins & Pr: reflux \\
\hline $\begin{array}{l}\mathrm{C} 1 \text { : telangiectasis or reticular veins }(\varnothing \\
\text { vein: }<3 \mathrm{~mm} \text { ) }\end{array}$ & Ep: primary & Ap: perforator veins & Po: obstruction \\
\hline C2: varicose veins ( $\varnothing$ vein: $\geq 3 \mathrm{~mm})$ & Es: secondary (postthrombotic) & Ad: deep veins & $\operatorname{Pr}, \mathrm{o}$ : reflux \& obstruction \\
\hline C3: oedema & & & $\begin{array}{l}\text { Pn: no venous pathophysiology } \\
\text { identifiable }\end{array}$ \\
\hline \multicolumn{4}{|l|}{ C4a: pigmentation \& eczema } \\
\hline \multicolumn{4}{|l|}{ C4b: lipodermatosclerosis \& atrophie } \\
\hline \\
\hline \multicolumn{4}{|l|}{ C5: healed venous ulcer } \\
\hline C6: active venous ulcer & & & \\
\hline
\end{tabular}

Beberapa terapi berikut dapat diberikan pada vena varikosa:

1. Stoking Kompresi

Peresepan stoking kompresi elastik termasuk tekanan dan panjang stoking. Tekanan yang diresepkan dipilih berdasarkan tingkat keparahan klinis: $20-30 \mathrm{mHg}$ untuk CEAP kelas 2-3, 30-40 mmHg untuk CEAP kelas 4-6, 40-50 $\mathrm{mmHg}$ untuk ulkus rekuren. Panjang stoking yang diresepkan biasanya knee-length stocking karena kepatuhan pasien lebih besar dan pengurangan gejala cukup baik. Penggunaan stoking setinggi paha atau pinggang diperlukan pada pasien dengan edema hingga di atas lutut. Pengukuran diameter ekstremitas juga diperlukan dalam peresepan. ${ }^{10,14}$

2. Terapi Farmakologi

Terdapat 4 kelompok obat yang dapat digunakan dalam penanganan insufisiensi vena kronis: coumarin ( $\alpha$-benzopyrone), flavonoid ( $\gamma$-benzopyrone), saponoside (ekstrak horse chestnut), dan ekstrak tanaman lain. Obatobatan ini memiliki efek venoaktif. Prinsip penggunaan obat-obat tersebut adalah untuk meningkatkan tonus vena dan permeabilitas kapiler, meskipun mekanisme kerjanya masih belum diketahui. Terapi farmakologi yang umum dipakai antara lain micronised purified flavonoid fraction (MPFF) dengan dosis 2 tablet MPFF $500 \mathrm{mg}$ perhari. Perbaikan gejala biasanya sudah tampak dalam 2 bulan penggunaan obat ini. ${ }^{10,15}$

Berdasarkan NICE Guideline untuk vena varikosa, penanganan vena varikosa sebagai berikut:

A. Intervensi

1. Skleroterapi

Skleroterapi diindikasikan untuk berbagai kondisi, antara lain: telangiektasia dan vena varikosa retikularis tanpa maupun dengan refluks superfisial. Terapi ini dilakukan dengan injeksi agen sklerosan (sodium tetradecyl sulfate, polidocanol, dsb) ke dalam vena varikosa dengan jarum kecil. Tujuannya adalah membuat perlukaan endotelial sehingga menyebabkan trombosis dan fibrosis. $5,10,16,17$

2. Endovenous ablation

Terapi ini menggunakan energi termal dalam bentuk radiofrekuensi atau laser. Teknik ini biasa digunakan untuk refluks vena saphena. Energi panas yang dihasilkan menyebabkan perlukaan termal lokal pada vena sehingga menyebabkan trombosis dan fibrosis. Anestesia (di sepanjang vena yang akan diterapi dengan teknik ini) dilakukan sebelum tindakan untuk mencegah luka bakar pada kulit dan mengurangi nyeri. ${ }^{10,18,19}$

Saat ini berkembang teknik baru yang mulai banyak digunakan, yaitu mechanochemical ablation (MOCA). Teknik ini memadukan endomechanical abrasion dengan ujung kawat dari kateter-berputar (komponen mekanik) dan endovenous chemical ablation (EVCA) dengan injeksi simultan agen 
sklerosan melalui kawat yang berputar (komponen kimia). Anestesia hanya diperlukan di titik tempat insersi kateter. $^{20-22}$

3. Terapi Bedah

c. Ligasi dan Stripping

Ligasi dan stripping dari v.saphena magna dapat diaplikasikan pada klasifikasi CEAP kelas 2-6 dengan refluks vena superfisial dan telah terbukti memberikan perbaikan yang signifikan pada hemodinamik vena, perbaikan gejala pada insufisiensi vena kronis tingkat lanjut, dan membantu penyembuhan ulserasi. ${ }^{8,23}$

d. Subfascial Endoscopic Perforator Surgery (SEPS)

Teknik bedah digunakan untuk meligasi vena perforator yang berkontribusi terhadap fokus tekanan tinggi pada vena superfisial dengan insufisiensi vena kronis tingkat lanjut. SEPS bertujuan untuk meligasi vena perforator dengan mencari akses dari sisi kaki yang jauh dari area dengan lipodermatosklerosis dan ulserasi. ${ }^{23,24}$

e. Valve Reconstruction

Rekonstruksi katup dari vena dalam dilakukan pada pasien-pasien dengan inkompetensi katup vena tingkat lanjut yang mengalami ulserasi rekuren dengan gejala yang parah. Operasi ini meliputi teknik terbuka yaitu open valvuloplasty serta teknik tertutup dengan transcommissural valvuloplasty. ${ }^{23,24}$

B. Non-intervensi

Stoking kompresi digunakan jika penanganan intervensi tidak dapat dilakukan. ${ }^{12}$

Evaluasi terapi dilakukan dengan skoring Revised Venous Clinical Severity Score (Tabel 2). Sistem skoring ini didesain sebagai pelengkap dari klasifikasi CEAP.9,25

Tabel 2. Revised Venous Clinical Severity Score (25)

\begin{tabular}{|c|c|c|c|c|}
\hline & None: 0 & Mild: 1 & Moderate: 2 & Severe: 3 \\
\hline $\begin{array}{l}\text { Pain } \\
\text { or other discomfort (ie, aching, } \\
\text { heaviness, fatigue, soreness, } \\
\text { burning) } \\
\text { Presumes venous origin }\end{array}$ & & $\begin{array}{l}\text { Occasional pain or other } \\
\text { discomfort (ie, not } \\
\text { restricting regular } \\
\text { daily activities) }\end{array}$ & $\begin{array}{l}\text { Daily pain or other } \\
\text { discomfort (ie, } \\
\text { interfering with but not } \\
\text { preventing regular daily } \\
\text { activities) }\end{array}$ & $\begin{array}{l}\text { Daily pain or discomfort } \\
\text { (ie, limits most } \\
\text { regular daily } \\
\text { activities) }\end{array}$ \\
\hline $\begin{array}{l}\text { Varicose veins } \\
\text { "Varicose" veins must be } \geq 3 \mathrm{~mm} \text { in } \\
\text { diameter to qualify in the standing } \\
\text { position. }\end{array}$ & & $\begin{array}{l}\text { Few: scattered } \\
\text { (ie, isolated branch } \\
\text { varicosities or clusters) } \\
\text { Also includes corona } \\
\text { phlebectatica (ankle } \\
\text { flare) }\end{array}$ & Confined to calf or thigh & Involves calf and thigh \\
\hline $\begin{array}{l}\text { Venous edema } \\
\text { Presumes venous origin }\end{array}$ & & $\begin{array}{l}\text { Limited to foot and } \\
\text { ankle area }\end{array}$ & $\begin{array}{l}\text { Extends above ankle but } \\
\text { below knee }\end{array}$ & $\begin{array}{l}\text { Extends to knee and } \\
\text { above }\end{array}$ \\
\hline $\begin{array}{l}\text { Skin pigmentation } \\
\text { Presumes venous origin } \\
\text { Does not include focal pigmentation } \\
\text { over varicose veins or } \\
\text { pigmentation due to other } \\
\text { chronic diseases } \\
\text { Inflammation }\end{array}$ & $\begin{array}{l}\text { None or } \\
\text { focal }\end{array}$ & $\begin{array}{l}\text { Limited to perimalleolar } \\
\text { area }\end{array}$ & $\begin{array}{l}\text { Diffuse over lower third of } \\
\text { calf }\end{array}$ & $\begin{array}{l}\text { Wider distribution } \\
\text { above lower third of } \\
\text { calf }\end{array}$ \\
\hline $\begin{array}{l}\text { More than just recent pigmentation } \\
\text { (ie, erythema, cellulitis, venous } \\
\text { eczema, dermatitis) } \\
\text { Induration }\end{array}$ & & $\begin{array}{l}\text { Limited to perimalleolar } \\
\text { area }\end{array}$ & $\begin{array}{l}\text { Diffuse over lower third of } \\
\text { calf }\end{array}$ & $\begin{array}{l}\text { Wider distribution } \\
\text { above lower third of } \\
\text { calf }\end{array}$ \\
\hline $\begin{array}{l}\text { Presumes venous origin of secondary } \\
\text { skin and subcutaneous changes } \\
\text { (ie, chronic edema with fibrosis, } \\
\text { hypodermitis). Includes white } \\
\text { atrophy and lipodermatosclerosis }\end{array}$ & & $\begin{array}{l}\text { Limited to perimalleolar } \\
\text { area }\end{array}$ & $\begin{array}{l}\text { Diffuse over lower third of } \\
\text { calf }\end{array}$ & $\begin{array}{l}\text { Wider distribution } \\
\text { above lower third of } \\
\text { calf }\end{array}$ \\
\hline Active ulcer number & 0 & 1 & 2 & $\geq 3$ \\
\hline $\begin{array}{l}\text { Active ulcer duration } \\
\text { (longest active) }\end{array}$ & $\mathrm{N} / \mathrm{A}$ & $<3 \mathrm{mo}$ & $>3$ mo but $<1$ y & Not healed for $>1 y$ \\
\hline $\begin{array}{l}\text { Active ulcer size } \\
\quad \text { (largest active) }\end{array}$ & $\mathrm{N} / \mathrm{A}$ & Diameter $<2 \mathrm{~cm}$ & Diameter $2-6 \mathrm{~cm}$ & Diameter $>6 \mathrm{~cm}$ \\
\hline Use of compression therapy & $\begin{array}{c}0 \\
\text { Not used }\end{array}$ & $\begin{array}{l}1 \\
\text { Intermittent use of } \\
\text { stockings }\end{array}$ & $\begin{array}{c}2 \\
\text { Wears stockings most days }\end{array}$ & $\begin{array}{l}\stackrel{3}{3} \\
\text { Full compliance: } \\
\text { stockings }\end{array}$ \\
\hline
\end{tabular}




\section{Daftar Pustaka}

1. Gloviczki P. The Layman' S Handbook of Venous Disorders. London: Hodder Arnold; 2009.

2. Darbari A, Chauhan P, Kumar A, Tandon S. Primary Varicose Vein of Upper Limb: A Rare Entity. Indian J Thorac Cardiovasc Surg. 2007;23(1):44.

3. Welch HJ, Villavicencio JL. Primary Varicose Veins of the Upper Extremity: A Report of Three Cases. J Vasc Surg. 1994;20(3):839-43.

4. Jain S, Jain P, Singh T, Aggarwal N, Singh A. Primary Varicose Veins of the Upper Extremity: A Case Report. Indian J Surg. 2004;66(3):169-71.

5. Corabian P, Harstall C. Sclerotherapy for Leg Varicose Veins. Canada; 2004.

6. Maggisano R, Harrison A. The Venous System. Ontario; 2004.

7. Ferri FF. Ferri`s Clinical Advisor. Mosby, an imprint of Elsevier Inc.; 2014.

8. Bergan JJ, Bunke-Paquette N. The Vein Book, Book 3. New York: Oxford University Press; 2014.

9. Krishnan S, Nicholls SC. Chronic Venous Insufficiency: Clinical Assessment and Patient Selection. Semin Interv Radiol. 2005;22(3):169-77.

10. Eberhardt RT, Raffetto JD. Chronic Venous Insufficiency. Circulation [Internet]. 2005;111:2398-409.

11. Davies MG, Lumsden AB. Chronic Venous Insufficiency. Minneapolis, Minnesota: Cardiotext Publishing; 2011.

12. Varicose veins in the legs. NICE Clin Guidel. 2013; 168(July).

13. Eklöf B, Rutherford R, Bergan J, Carpentler P, Gloviczki P, Kistner R, et al. Revised of the CEAP Classification fo Chronic Venous Disorders. J Vasc Surg. 2004;40(6):1248-52.

14. Labropoulos N, Stansby G. Venous and Lymphatic Disease. New York: Taylor \& Francis Group; 2006.
15. Lyseng-Williamson KA, Perry CM. Micronised Purified Flavonoid Fraction: A Review of its Use in Chronic Venous Insufficiency, Venous Ulcers and Haemorrhoids. Drugs. 2003;63(1):71-100.

16. Ceratti S, Okano FM, Pontes ABG, Pontes AL, Nastri R. Ultrasound-guided Foam Sclerotherapy in the Treatment of Chronic Venous Insufficiency. Radiol Bras. 44(3):167-71.

17. Ultrasound-guided Foam Sclerotherapy for Varicose Veins. Manchester; 2013.

18. Radiofrequency Ablation of Varicose Veins. Manchester; 2003.

19. Endovenous Laser Treatment of the Long Saphenous Vein. Manchester; 2004.

20. Eekeren RRJP Van, Boersma D, Elias S, Holewijn S, Werson DAB, Vries J-PPM De, et al. Endovenous Mechanochemical Ablation of Great Saphenous Vein Incompetence Using the ClariVein Device: A Safety Study. J Endovasc Ther. 2011;18:328-34.

21. Mueller RL, Raines JK. Vascular and Endovascular Surgery ClariVein Mechanochemical Ablation : Background and Procedural Details. Vasc Endovascular Surg. 2013;47(3):195-206.

22. Endovenous Mechanochemical Ablation for Varicose Veins. Manchester; 2013.

23. Padberg FJ, Pappas P, Araki C, Back T, Hobson R. Hemodynamic and Clinical Improvement after Superficial Vein Ablation in Primary Combined Venous Insufficiency with Ulceration. J Vasc Surg. 1996;24(5):711-8.

24. MacKenzie R, Allan P, Ruckley C, Bradbury A. The Effect of Long Saphenous Vein Stripping on Deep Venous Reflux. Eur J Vasc Endovasc Surg. 2004;28(1):104-7.

25. Vasquez MA, Rabe E, McLafferty RB, Shortell CK, Marston WA, Gillespie D, et al. Revision of the Venous Clinical Severity Score : Venous Outcomes Consensus Statement : Special Communication of the American Venous Forum Ad Hoc Outcomes Working Group. J Vasc Surg. 2010;52(5):1387-96. 